\title{
Supply Chain Finance Decision Analysis with a Partial Credit Guarantee Contract
}

\author{
Yueliang Su, Baoyu Zhong \\ School of Business, South China University of Technology, Guangzhou, China \\ Email: 490943753@qq.com
}

How to cite this paper: Su, Y.L. and Zhong, B.Y. (2017) Supply Chain Finance Decision Analysis with a Partial Credit Guarantee Contract. Journal of Applied Mathematics and Physics, 5, 1355-1369. https://doi.org/10.4236/jamp.2017.56112

Received: May 24, 2017

Accepted: June 26, 2017

Published: June 29, 2017

Copyright (C) 2017 by authors and Scientific Research Publishing Inc. This work is licensed under the Creative Commons Attribution International License (CC BY 4.0).

http://creativecommons.org/licenses/by/4.0/

\section{(c) (i) Open Access}

\begin{abstract}
The innovation of supply chain financial services can alleviate the plight of SMEs financing difficulties. In the aspect of supply chain finance model, there is a credit guarantee financing model, which is different from the simple external financing and internal financing mode of supply chain. Based on this, this paper studies the decision-making of supply chain finance under the partial credit guarantee of core enterprises. First of all, the paper constructs a simple supply chain financing model, consisting of a bank, a core enterprise and a retailer. And then, considering the credit guarantee financing model, calculate the expected profit function. Stackelberg game model is used to give the optimal decision of each subject in decentralized system and the optimal decision in centralized system. Finally, in order to make a more specific and detailed study on the profit and decision-making based on the credit guarantee financing model, the important parameters of the model are analyzed. Through the calculation, it is proved that under the credit guarantee of the core enterprise, the retailer has the optimal ordering strategy, and the core enterprise has the best wholesale price. The influences of the partial credit guarantee coefficient and the retailer's loan coefficient on the supply chain finance decision-making are also studied.
\end{abstract}

\section{Keywords}

Supply Chain Finance, Decision-Making, Partial Credit Guarantee

\section{Introduction}

Considering the risk of SMEs, financial institutions have been cautious about the financing of SMEs. Supply chain finance, through the integration of information chain, capital chain, logistics chain, and so on, forms an internal circulation ecosystem, which is a breakthrough to solve the financing difficulties of SEMs. In the development of supply chain finance in China, the evaluation of the en- 
terprise's credit, collateral is basically carried out by the bank or the bank commissioned by third parties. Therefore, the main mode of supply chain finance in China is banking-oriented model. At the same time, as the most powerful leading enterprise in the supply chain, the core enterprise can help to improve the whole supply chain with the advantage of information and credit. The credit guarantee financing model, providing credit guarantee for the downstream retailers, gradually appeared.

About supply chain decision-making and coordination, most scholars study the wholesale price contract, risk sharing, revenue sharing, buy back contract, rebate contract and other contracts based on two echelon supply chain, retailermanufacturer or supplier-manufacturer.

In the supply chain, only a small number of scholars consider the impact of financial constraints on the supply chain decisions. The research about the decision-making of three echelon supply chain, retailer-manufacturer-bank, is also less. In this paper, the credit guarantee contract is integrated into the supply chain finance model, to study the decision-making of supply chain finance.

\section{Literature Review}

In recent years, many scholars have used the basic newsboy model and the Stackelberg game model to do quantitative research on the supply chain with capital constraints. Dada \& Hu [1] consider the newsboy model of SCF with capital constraints, and point out that the problem of supply chain financing strategy is mainly focused on the optimal inventory management of retailers when they have capital constraints. Srinivasa [2] further considers the problem of single stage financing decision in two echelon supply chain with capital constraints, which shows that the performance of joint financing is greater than separate financing's. Kouvelis and Zhao [3] consider the financing decision problem of supply chain with a capital constraint in the game framework that manufacturer led. Yan et al. (2014) [4] establish a multi-agent game model in which the bank acts as a leader and the manufacturer acts as the sub-leader, and study the joint financing decision problem of the supply chain financial system. Nina et al. [5] design a partial credit guarantee contract for SCF, incorporating the bank credit financing and manufacturer's trade credit guarantee, to analyze its equilibrium financing strategies. Yan \& Sun [6] study the optimal strategy of the capital-constrained retailer in SCF through warehouse receipt pledge under the uncertain demand environment. Considering the credit limit and the ruin probability of the retailer, the optimal financing interest rate, the retailer's optimal order decision and the optimal wholesale price of the manufacturer are analyzed. Lu et al. [7] establish a multi-stage supply chain decision model including a supplier, a downstream manufacturer and a financial institution according to accounts receivable financing model of supply chain, and study the decision-making problem of the firms with and without financing. Yi \& Zhou [8] consider a two echelon supply chain consisting of a single supplier and a single retailer. The paper analyses the bank's loan to value ratios when the retailer 
pledging his order contract in a newsboy supply chain. Li \& Lou [9] establish a one-to-one supply chain dynamic game model with a capital-constrained supplier, and analyze the effectiveness to the improvement of the efficiency of supply chain by retailer's advance payment. Lin Chen et al. [10] study the pricing and effort decisions of a supply chain with single manufacturer and single retailer. The results imply that the uncertainty degree of sales effort elasticity has an outstanding influence on the pricing and effort decisions, whereas the uncertainty degree of price elasticity has a modest impact on these decisions. Z. Liu et al. [11] find that the retailer's optimal order quantity is determined by the inverse distribution of the external demand and the confidence level considering a contract-design problem for two competing heterogeneous suppliers working with a common retailer. $\mathrm{H}$. Chen et al. [12] consider the optimal selling problem of a supplier who sells the same product to two competing retailers under two types of uncertainty-the selling costs of retailers and external demand and the results demonstrate that higher risk levels correlate with lower belief-degree costs of the two retailers and higher belief-degree sizes of the market.

On the basis of the scholars' research, the credit guarantee contract is integrated into the supply chain finance model. This paper innovatively set up the credit guarantee coefficient and retailer's loan coefficient and studied the influence of coefficients on decision-making of supply chain finance.

\section{Model Description}

Supply chain financing is generally short, this paper establishes a single order cycle of supply chain finance model including a capital-constrained retailer, a core manufacturers and a bank. Then we formulate a Stackelberg game model in which the bank acts as a leader.

\subsection{Variable Definitions and Parameters}

In order to describe the analysis model easily, the relevant variables and parameters are defined as follows.

(1) $p$ : Unit retail price

(2) c. Unit manufacturing cost

(3) $w$ :The manufacturer's wholesale price

(4) a: The retailer's loan coefficient, $0 \leq a \leq w$

(5) $B$ : The retailer's loan amount, $B=a q$

(6) $R_{r}$ : The bank's endogenous interest rate

(7) $R_{f}$ : The risk-free interest rate

(8) $\lambda$ : The credit guarantee coefficient, $0<\lambda<1$

(9) $q$ : The retailer's order quantity

(10) $x$ : Random demand

(11) $F(x)$ : Distribution function of random demand

(12) $f(x)$ : density function of $F(x)$

Let $q, w, R_{r}$ respectively be the decision variables and $q^{*}, w^{*}, R_{r}^{*}$ respectively be the retailer's optimal order quantity, manufacturer's optimal whole- 
sale price, and the bank's optimal interest rate.

\subsection{Model Assumptions}

In order to describe the analysis model easily, make the following assumptions.

1) The supply chain finance system considers only one order cycle, consisting of a retailer, a manufacturer and a bank.

2) It is assumed that the distribution function $F(x)$ is a continuous function which is consistent with the increasing rate of failure distribution (IGFR).

3) It is assumed that retailer only sells a single product and the manufacturer can fully meet the demand of the retailer and the bank can meet the retailer's loan.

4) Assuming that the retailer's financing volume is proportional to the order quantity and let the loan coefficient be parameter a, where $B=a q$.

5) Assume that the product has no residual value and $p \geq a\left(1+R_{r}\right)$.

6) In the supply chain finance system, the participants are risk neutral, and the goal is to maximize the expected profit.

\subsection{The Model Framework}

A single cycle supply chain financial system consisting of a retailer, a manufacturer and a bank is established. The capital-constrained retailer needs to apply for a loan. The manufacturer provides a certain credit guarantee for the retailer's loan, who will pay a certain proportion of the remaining loan when the retailer can't repay. Bank is the leader of supply chain finance system.

Supply chain finance process are assumed by Figure 1.

1) First of all, as the leader of the supply chain financial system, the bank gives an appropriate loan interest rate $R_{r}$

2) Secondly, the sub-leader decides a wholesale price w when the bank has given the interest rate.

3) Then, the retailer makes a decision on the order quantity $q$ after the bank gave interest rate $R_{r}$ and the manufacturer decided wholesale price w. At the same time, the retailer apply to the bank for a loan $B=a q$ because of capital constraints.

4) At the end of the period, the retailer repay the loan according to sales. If the retailer has the ability to repay the loan, the retailer bears all the principal

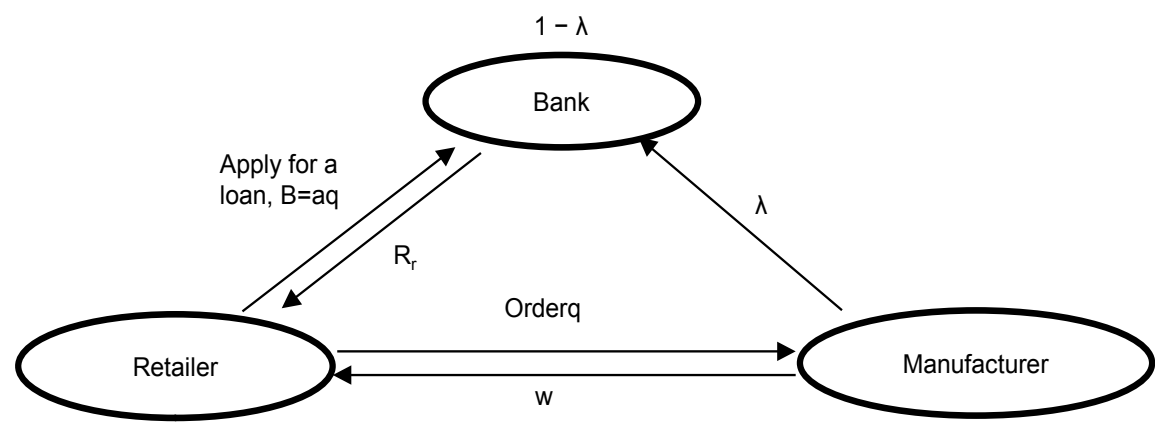

Figure 1. Supply chain finance process. 
and interest. If the retailer's total sales are insufficient to repay all of the loan, the bank and the manufacturer take up the remaining loan together. The manufacturer bears $\lambda$ of the retailer's remaining loan.

We formulate a multilevel Stackelberg game model to characterize the interactions among the three SCF participants, which can be expressed as follows.

$$
\left\{\begin{array}{l}
(L) \max _{R_{r}}\left[\pi_{B}\left(R_{r} ; q, w, x\right)\right] \\
(S L) \max _{w}\left[\pi_{M}\left(w ; q, R_{r}, x\right)\right] \\
(F) \max _{q}\left[\pi_{R}\left(q ; R_{r}, w, x\right)\right]
\end{array}\right.
$$

\section{The Supply Chain Finance System's Profits}

\section{Proposition 1}

When the random demand $x$ is greater than the minimum realized demand $x_{1}$, the retailer can pay the principal and interest by itself at the end of the period, where $x_{1}=a q\left(1+R_{r}\right) / p$. And $x_{1} \leq q$ is also obtained.

Proof: At the end of the period, the retailer need to repay the principal and interest i.e. $a q\left(1+R_{r}\right)$.

If $x<q$, the total sales of the retailer are $p x$. Then, $p x \geq p x_{1}=a q\left(1+R_{r}\right)$ holds for $x \geq x_{1}=a q\left(1+R_{r}\right) / p$.

If $x \geq q$, the total sales of the retailer are $p q$. Then, $p q \geq p x_{1}=a q\left(1+R_{r}\right)$ is obtained for $p \geq a q\left(1+R_{r}\right)$.

Hence, $x_{1}=a q\left(1+R_{r}\right) / p \leq q$ holds for $p x_{1}=a q\left(1+R_{r}\right) \leq p q$.

\subsection{The Supply Chain Finance System's Profits in Decentralized System}

At the beginning of the period, the manufacturer gives the wholesale price $\mathrm{w}$, and the retailer orders quantity $q$. Due to financial constraints, the retailer applies for a loan $B=a q$ from bank and its own funds are $w q=a q$. The bank gives a loan interest rate $R_{r}$ and signs a credit guarantee contract with the manufacturer who bears $\lambda$ of the retailer's remaining loan.

At the end of the period, the retailer's sales revenue is $\min \{p x, p q\}$, who need to repay the principal and interest $a q\left(1+R_{r}\right)$. If the retailer can't repay the principal and interest, i.e. $x<x_{1}$, the remaining loan is $a q\left(1+R_{r}\right)-p x$ that the retailer can't repay. The bank and the manufacturer take up the remaining loan together. The manufacturer bears $\lambda$ of the retailer's remaining loan and the bank bears $1-\lambda$ of the retailer's remaining loan.

1) The retailer's profit function can be expressed as in Equation (1)

$$
R=\left\{\begin{array}{lc}
-(w q-a q), & x \leq x_{1} \\
p x-a q\left(1+R_{r}\right)-(w q-a q), & x_{1}<x<q \\
p q-a q\left(1+R_{r}\right)-(w q-a q), & q \leq x
\end{array}\right.
$$

The retailer's expected profit function can be expressed as in Equation (2) 


$$
\begin{aligned}
\pi_{R}= & E(R) \\
= & \int_{0}^{x_{1}}-(w q-a q) f(x) \mathrm{d} x+\int_{x_{1}}^{q}\left(p x-a q\left(1+R_{r}\right)-(w q-a q)\right) f(x) \mathrm{d} x \\
& +\int_{q}^{\infty}\left(p x-a q\left(1+R_{r}\right)-(w q-a q)\right) f(x) \mathrm{d} x
\end{aligned}
$$

2) The manufacturer's profit function can be expressed as in Equation (3)

$$
M= \begin{cases}(w-c) q-\lambda\left[a q\left(1+R_{r}\right)-p x\right], & x<x_{1} \\ (w-c) q, & x \geq x_{1}\end{cases}
$$

The manufacturer's expected profit function can be expressed as in Equation (4)

$$
\begin{aligned}
\pi_{M} & =E(M) \\
& =\int_{0}^{x_{1}}\left((w-c) q-\lambda\left[a q\left(1+R_{r}\right)-p x\right]\right) f(x) \mathrm{d} x+\int_{x_{1}}^{\infty}(w-c) q f(x) \mathrm{d} x
\end{aligned}
$$

3) The bank's profit function can be expressed as in Equation (5)

$$
B= \begin{cases}a q\left(R_{r}-R_{f}\right)-(1-\lambda)\left[a q\left(1+R_{r}\right)-p x\right], & x<x_{1} \\ a q\left(R_{r}-R_{f}\right), & x \geq x_{1}\end{cases}
$$

The bank's expected profit function can be expressed as in Equation (6)

$$
\begin{aligned}
\pi_{B}=E(B)= & \int_{0}^{x_{1}}\left(a q\left(R_{r}-R_{f}\right)-(1-\lambda)\left[a q\left(1+R_{r}\right)-p x\right]\right) f(x) \mathrm{d} x \\
& +\int_{x_{1}}^{\infty} a q\left(R_{r}-R_{f}\right) f(x) \mathrm{d} x
\end{aligned}
$$

\subsection{The Supply Chain Finance System's Profit in Centralized System}

The supply chain finance system's profit function can be expressed as in Equation (7)

$$
S= \begin{cases}p x-c q-a q R_{f}, & x<q \\ p q-c q-a q R_{f}, & x \geq q\end{cases}
$$

The supply chain finance system's expected profit function can be expressed as in Equation (8)

$$
\pi_{S}=E(S)=\int_{0}^{q}\left(p x-c q-a q R_{f}\right) f(x) \mathrm{d} x+\int_{q}^{\infty}\left(p q-c q-a q R_{f}\right) f(x) \mathrm{d} x
$$

\section{The Supply Chain Finance System’s Optimal Decisions}

We solve the model via backward induction to determine the optimal decisions of the supply chain finance system.

\subsection{The Supply Chain Finance System's Decisions in Decentralized System}

\section{Proposition 2}

Given the unit retail price $p$, the manufacturer's wholesale price $w$, unit manufacturing cost $c$, retailer's loan coefficient $a$, the bank's endogenous interest rate $R_{r}$ and the risk-free interest rate $R_{f}$, for IGFR distributions of demand, the 
capital-constrained retailer's unique and optimal order quantity that satisfies $q^{*}=F^{-1}\left(\frac{p-(w-a)-a\left(1+R_{r}\right) \overline{F\left(x_{1}^{*}\right)}}{p}\right)$, where $x_{1}^{*}=a q^{*}\left(1+R_{r}\right) / p$.

\section{Proof:}

From Equation (2), taking the first-order and second-order derivative of $\pi_{R}$ with respect to $q$, it follows that

$$
\begin{aligned}
\frac{\mathrm{d} \pi_{R}}{\mathrm{~d} q} & =-(w-a)-a\left(1+R_{r}\right) \overline{F\left(x_{1}\right)}+p \overline{F(q)} \\
\frac{\mathrm{d}^{2} \pi_{R}}{\mathrm{~d} q^{2}} & =\frac{a^{2}\left(1+R_{r}\right)^{2}}{p} f\left(x_{1}\right)-p f(q)
\end{aligned}
$$

If the distribution of demand is IGFR, $f\left(x_{1}\right) \leq f(q)$ holds for $x_{1} \leq q$. Besides, $\frac{a^{2}\left(1+R_{r}\right)^{2}}{p} \leq a\left(1+R_{r}\right) \leq p$ holds for $a\left(1+R_{r}\right) \leq p$. Hence, we have $\frac{\mathrm{d}^{2} \pi_{R}}{\mathrm{~d} q^{2}} \leq 0$. From the first-order condition of $\frac{\mathrm{d} \pi_{R}}{\mathrm{~d} q}=0$, we have

$$
q^{*}=F^{-1}\left(\frac{p-(w-a)-a\left(1+R_{r}\right) \overline{F\left(x_{1}^{*}\right)}}{p}\right)
$$

\section{Lemma 1}

$$
\frac{\mathrm{d} q^{*}}{\mathrm{~d} w}<0, \frac{\mathrm{d} x_{1}^{*}}{\mathrm{~d} w}<0, \frac{\mathrm{d} q^{*}}{d R_{r}}<0
$$

\section{Proof:}

From Proposition 2, we have

$$
F\left(q^{*}\right)=\frac{p-(w-a)-a\left(1+R_{r}\right) \overline{F\left(x_{1}\left(q^{*}\right)\right)}}{p}
$$

Taking the first-order derivative of $F\left(q^{*}\right)$ with respect to $w$, we have

$$
\frac{\mathrm{d} q^{*}}{\mathrm{~d} w} f\left(q^{*}\right)=\frac{-p+a^{2}\left(1+R_{r}\right)^{2} f\left(x_{1}\left(q^{*}\right)\right) \frac{\mathrm{d} q^{*}}{\mathrm{~d} w}}{p^{2}} .
$$

Hence,

$$
\frac{\mathrm{d} q^{*}}{\mathrm{~d} w}=\frac{p}{a^{2}\left(1+R_{r}\right)^{2} f\left(x_{1}\left(q^{*}\right)\right)-p^{2} f\left(q^{*}\right)} .
$$

$\frac{\mathrm{d} q^{*}}{\mathrm{~d} w}<0$ holds for $a^{2}\left(1+R_{r}\right)^{2} f\left(x_{1}\left(q^{*}\right)\right)-p^{2} f\left(q^{*}\right)<0$ and $p>0$. It is obvious that

$$
\frac{\mathrm{d} x_{1}^{*}}{\mathrm{~d} w}=\frac{a\left(1+R_{r}\right)}{p} \frac{\mathrm{d} q^{*}}{\mathrm{~d} w}<0 .
$$


$\frac{\mathrm{d} q^{*}}{\mathrm{~d} R_{r}}<0$ can be obtained too.

\section{Proposition 3}

Given the unit retail price $p$, unit manufacturing cost $c$, retailer's loan coefficient $a$, the bank's endogenous interest rate $R_{r}$, the risk-free interest rate $R_{f}$, the credit guarantee coefficient $\lambda$ and the optimal order quantity

$$
q^{*}=F^{-1}\left(\frac{p-(w-a)-a\left(1+R_{r}\right) \overline{F\left(x_{1}\right)}}{p}\right),
$$

for IGFR distributions of demand, the manufacturer's unique and optimal wholesale price that satisfies

$$
w^{*}=\frac{\lambda a\left(1+R_{r}\right) F\left(x_{1}^{*}\right) \frac{\mathrm{d} q^{*}}{\mathrm{~d} w^{*}}-q^{*}}{\frac{\mathrm{d} q^{*}}{\mathrm{~d} w^{*}}}+c .
$$

\section{Proof:}

The wholesale price has a definite closed interval that $w \in[c, p]$, and the manufacturer's profit function is continuous on the closed interval, there must be a maximum expected profit.

Considering $q^{*}$ and $x_{1}^{*}=\frac{a q^{*}\left(1+R_{r}\right)}{p}$ from Proposition 2 and Equation (4),

$$
\begin{aligned}
\pi_{M}\left(q^{*}\right) & =E(M) \\
& =\int_{0}^{x_{1}^{*}}\left((w-c) q^{*}-\lambda\left[a q^{*}\left(1+R_{r}\right)-p x\right]\right) f(x) \mathrm{d} x+\int_{x_{1}^{*}}^{\infty}(w-c) q^{*} f(x) \mathrm{d} x
\end{aligned}
$$

Taking the first-order derivative of $\pi_{M}\left(q^{*}\right)$ with respect to $w$,

$$
\begin{aligned}
\frac{\mathrm{d} \pi_{M}}{\mathrm{~d} w} & =q^{*}+(w-c) \frac{\mathrm{d} q^{*}}{\mathrm{~d} w}-\lambda a\left(1+R_{r}\right) F\left(x_{1}^{*}\right) \frac{\mathrm{d} q^{*}}{\mathrm{~d} w} \\
& =q^{*}+\left(w-c-\lambda a\left(1+R_{r}\right) F\left(x_{1}^{*}\right)\right) \frac{\mathrm{d} q^{*}}{\mathrm{~d} w} .
\end{aligned}
$$

$q^{*}$ and $\left(w-c-\lambda a\left(1+R_{r}\right) F\left(x_{1}^{*}\right)\right) \frac{\mathrm{d} q^{*}}{\mathrm{~d} w}$ monotonically decrease for $\frac{\mathrm{d} q^{*}}{\mathrm{~d} w}<0$ and hence, $\frac{\mathrm{d}^{2} \pi_{M}}{\mathrm{~d} w^{2}}<0$. From the first-order condition of $\frac{\mathrm{d} \pi_{M}}{\mathrm{~d} w}=0$, we have $w^{*}=\frac{\lambda a\left(1+R_{r}\right) F\left(x_{1}^{*}\right) \frac{\mathrm{d} q^{*}}{\mathrm{~d} w^{*}}-q^{*}}{\frac{\mathrm{d} q^{*}}{\mathrm{~d} w^{*}}}+c$

\section{Proposition 4}

Given the unit retail price $p$, unit manufacturing cost $c$, retailer's loan coefficient $a$, the risk-free interest rate $R_{f}$, the credit guarantee coefficient $\lambda$, the optimal order quantity $q^{*}=F^{-1}\left(\frac{p-(w-a)-a\left(1+R_{r}\right) \overline{F\left(x_{1}\right)}}{p}\right)$ and the optim- 
al wholesale price $w^{*}=\frac{\lambda a\left(1+R_{r}\right) F\left(x_{1}^{*}\right) \frac{\mathrm{d} q^{*}}{\mathrm{~d} w^{*}}-q^{*}}{\frac{\mathrm{d} q^{*}}{\mathrm{~d} w^{*}}}+c$, for IGFR distributions of demand, the expected profit of the bank increases with the loan interest rate when $R_{r}<(1-\lambda) a\left(1+R_{r}\right) F\left(x_{1}^{*}\right)+R_{f}$

Proof:

$$
\frac{\mathrm{d} \pi_{B}}{\mathrm{~d} R_{r}}=\frac{\mathrm{d} \pi_{B}}{\mathrm{~d} q^{*}} \frac{\mathrm{d} q^{*}}{\mathrm{~d} R_{r}}
$$

From Lemma $1, \frac{\mathrm{d} q^{*}}{\mathrm{~d} R_{r}}<0$. Hence, $\frac{\mathrm{d} \pi_{B}}{\mathrm{~d} R_{r}}$ can be transformed into $\frac{\mathrm{d} \pi_{B}}{\mathrm{~d} q^{*}}$. Taking the first-order derivative of $\mathrm{d} \pi_{B}$ with respect to $q^{*}$

$$
\frac{\mathrm{d} \pi_{B}}{\mathrm{~d} q^{*}}=a\left(R_{r}-R_{f}\right)-(1-\lambda) a\left(1+R_{r}\right) F\left(x_{1}^{*}\right)
$$

$\frac{\mathrm{d} \pi_{B}}{\mathrm{~d} q^{*}}<0$ for $R_{r}<(1-\lambda) a\left(1+R_{r}\right) F\left(x_{1}^{* *}\right)+R_{f}$. And then $\frac{\mathrm{d} \pi_{B}}{\mathrm{~d} R_{r}}>0$ for $\frac{\mathrm{d} \pi_{B}}{\mathrm{~d} q^{*}}<0$ and $\frac{\mathrm{d} q^{*}}{\mathrm{~d} R_{r}}<0$.

\subsection{The Supply Chain Finance System's Decision in Centralized System}

\section{Proposition 5}

In centralized system, given the unit retail price $p$, unit manufacturing cost $c$, retailer's loan coefficient $a$ and the risk-free interest rate $R_{f}$, for IGFR distributions of demand, the capital-constrained retailer's unique and optimal order quantity that satisfies $q^{*}=F^{-1}\left(\frac{p-c-a R_{f}}{p}\right)$.

\section{Proof:}

From Equation (8), taking the first-order and second-order derivative of $\pi_{S}$ with respect to $q$, it follows that

$$
\begin{aligned}
\frac{\mathrm{d} \pi_{S}}{\mathrm{~d} q} & =p \overline{F(q)}-c-a R_{f} \\
\frac{\mathrm{d}^{2} \pi_{S}}{\mathrm{~d} q^{2}} & =-p f(q)
\end{aligned}
$$

It is obvious that $\frac{\mathrm{d}^{2} \pi_{S}}{\mathrm{~d} q^{2}}=-p f(q) \leq 0$.

From the first-order condition of $\frac{\mathrm{d} \pi_{S}}{\mathrm{~d} q}=0$, we have $q_{S}^{*}=F^{-1}\left(\frac{p-c-a R_{f}}{p}\right)$

\section{Numerical Example}

Assuming that distribution function of random demand obeys uniform distribution with a mean of 200 , the unit retail price $p=8$, manufacturer's wholesale 
price $c=6$, the risk-free interest rate $R_{f}=0.03$.

Given the retailer's loan coefficient $a=6$ and credit guarantee coefficient $\lambda=0.9$, Figure 2 describes the change of retailer's optimal order quantity with the loan interest rate $R_{r}$ in decentralized and centralized system. Figure 3 describes the change of SCF participants and system's optimal profit with the loan interest rate $R_{r}$ in decentralized and centralized system.

(1) From Proposition 5, the retailer's optimal order quantity is only related to $p, c, a, R_{f}$ in centralized system. Therefore, the retailer's optimal order quantity and the optimal profit of the supply chain finance system do not change with the loan interest rate $R_{r}$.

(2) After the game analysis, the retailer's optimal order quantity decreases with the increase of the loan interest rate $R_{r}$ in the decentralized system. On the other hand, the bank's optimal profit increases with the increase of loan interest rate $R_{r}$, and the growth rate slows down with the increase of loan interest rate $R_{r}$. The retailer, manufacturer and SCF system's optimal profit decrease with the increase of the loan interest rate. In order to encourage retailer and manufacturer, the bank should choose the appropriate interest rate $R_{r}$.

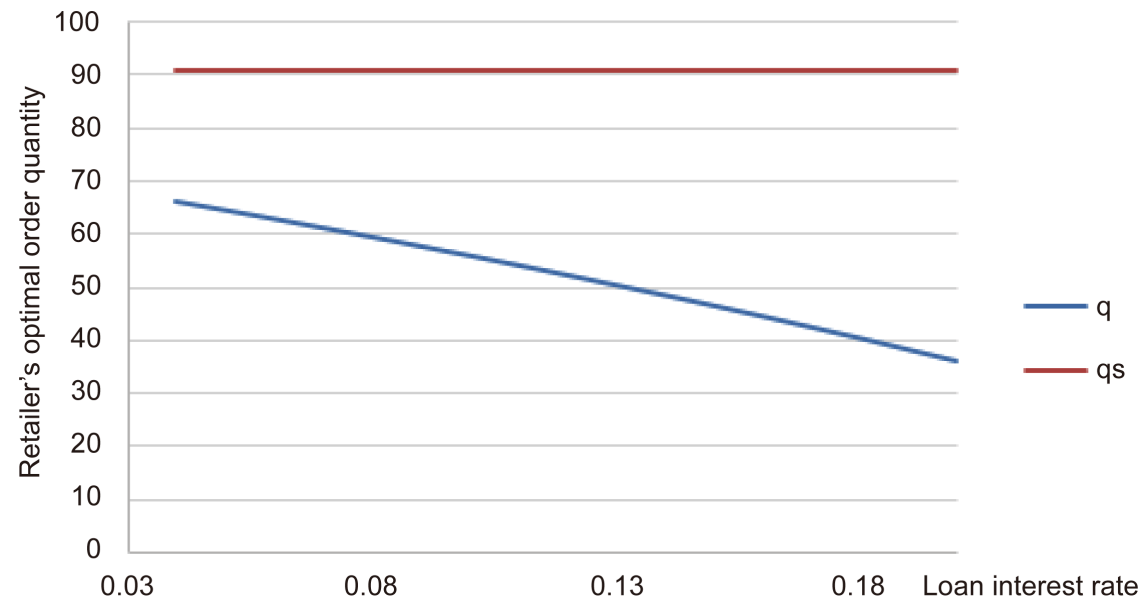

Figure 2. Retailer's optimal order quantity underdifferent loan interest rate.

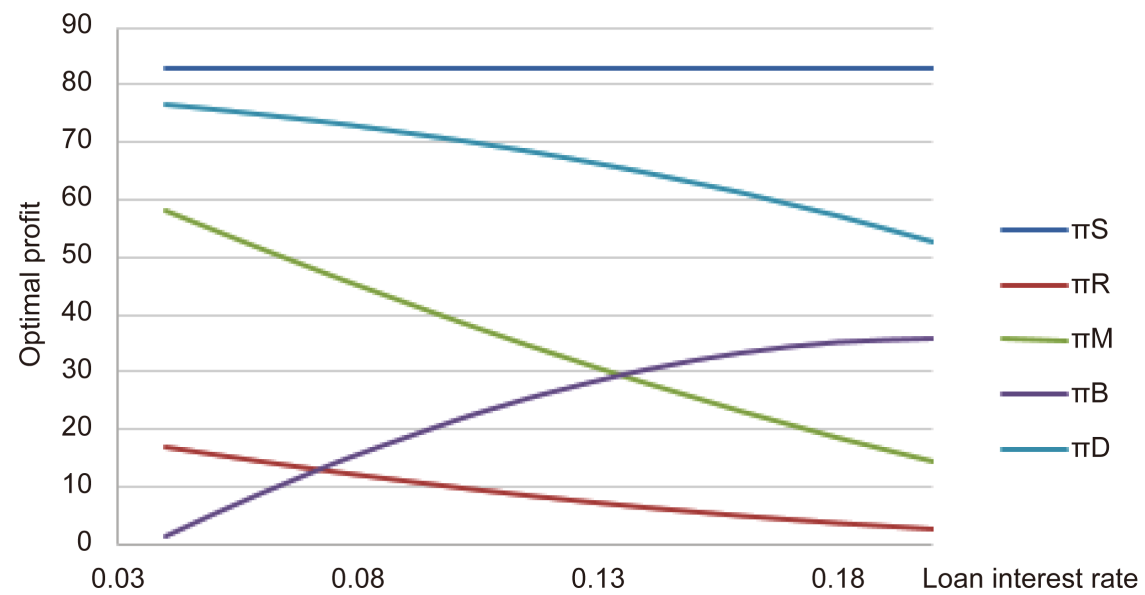

Figure 3. SCF participants and system's optimal profit under different loan interest rate. 
(3) The bank's optimal profit is higher than the retailer's one after the bank's interest rate reaches about 0.07 , and the bank's optimal profit is higher than the manufacturer's one after the bank's interest rate reaches about 0.14.

(4) According to Figure 3, the optimal profit of the supply chain financial system in centralized system is always higher than the sum of the three SCF participants' optimal profit in the decentralized system. The higher $R_{r}$ is, the larger optimal profit gap between the decentralized and centralized system is.

Given the bank's endogenous interest rate $R_{r}$ and credit guarantee coefficient $\lambda=0.9$, Figure 4 describes the change of retailer's optimal order quantity with the retailer's loan coefficient $a$ in decentralized and centralized system. Figure 5 describes the change of SCF participants and system's optimal profit with the retailer's loan coefficient $a$ in decentralized and centralized system.

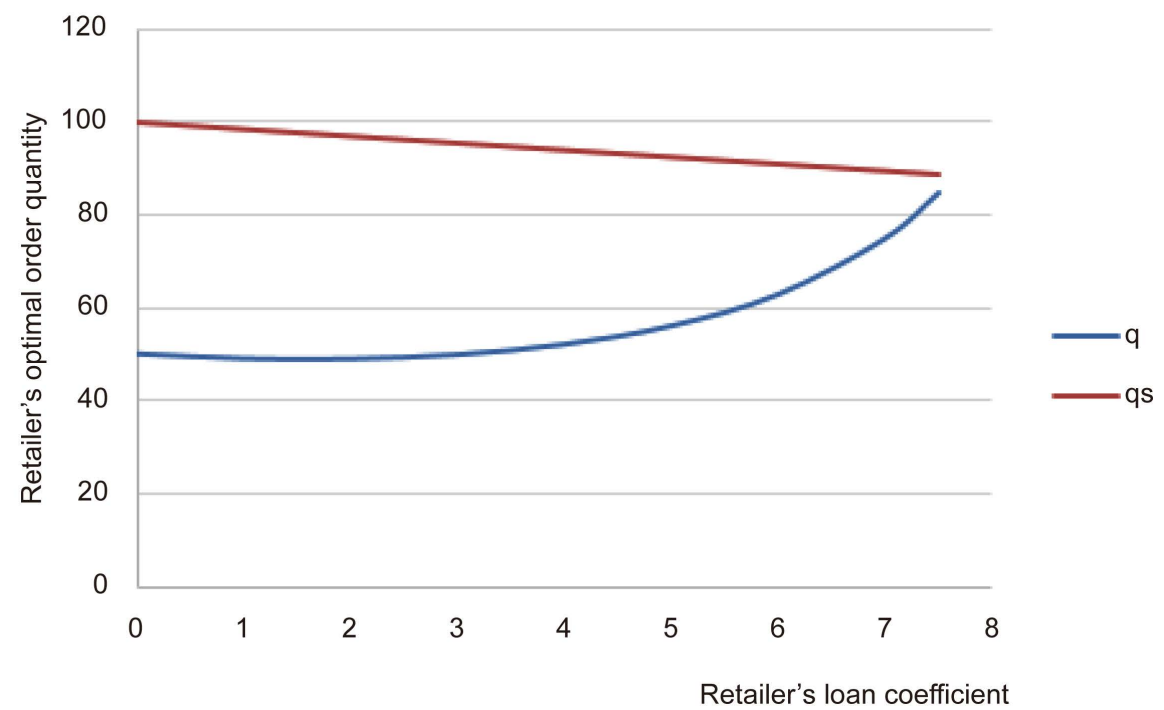

Figure 4. Retailer's optimal order quantityunder differentretailer's loan coefficient.

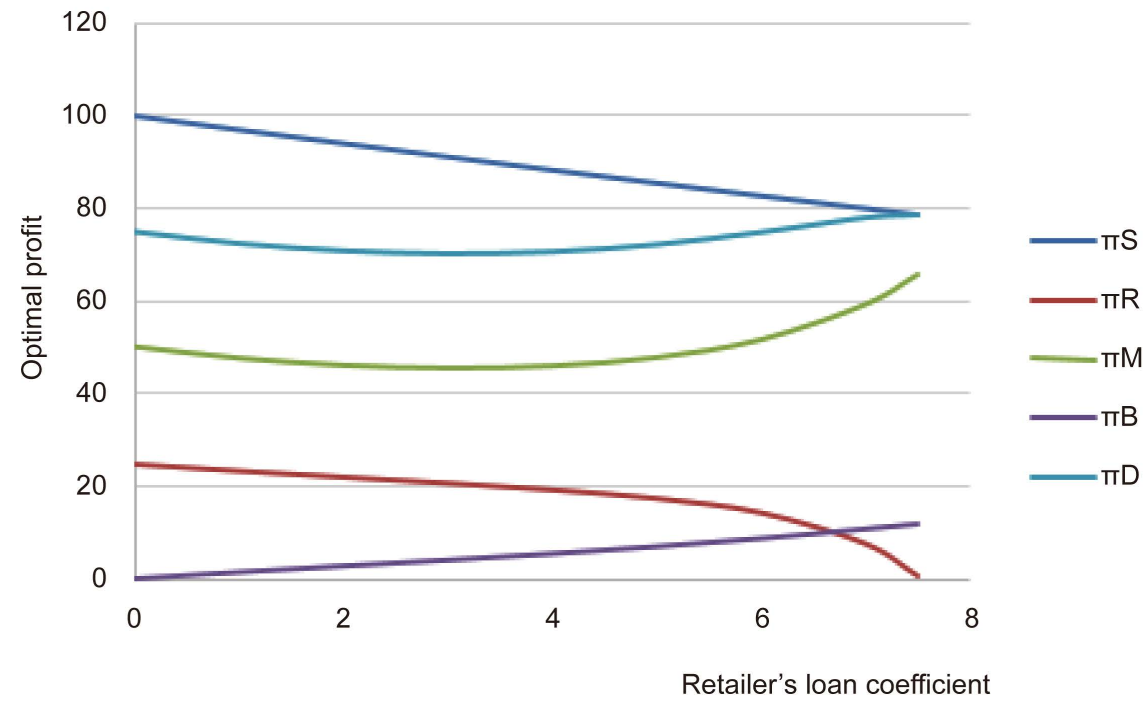

Figure 5. SCF participants and system's optimal profit under differentretailer's loan coefficient. 
1) In centralized system, the retailer's optimal order quantity and the optimal profit of the supply chain finance system decrease with the increase of the loan coefficient $a$.

2) In decentralized system, the retailer's optimal order quantity decreases with the increase of $a$, and then increases at a faster rate. The bank's optimal profit increases with the increase of $a$. And with the increase of $a$, the retailer's optimal profit firstly declines at a faster rate, then decreases slowly, and finally decreases sharply. The manufacturer's optimal profit decreases with the increase of $a$, and then increases at a faster rate. The variation tendency of the three SCF participants' total optimal profit is approximately the same as that of the manufacturer.

3) The bank's optimal profit and the retailer's optimal profit are equal at about 6.5 of $a$.

4) From Figure 5, the optimal profit of the supply chain financial system in centralized system is always higher than the sum of the three SCF participants' optimal profit in the decentralized system too. When the the loan amount is the same as the order cost $(a q=w q)$, that is, the retailer's own capital is zero, the optimal profit of the SCF system in centralized system is equal to the sum of the three SCF participants' optimal profit in the decentralized system. Appropriately increasing retailer's loan coefficient can narrow the optimal profit gap between the decentralized and centralized system.

Given the bank's endogenous interest rate $R_{r}=0.06$ and the retailer's loan coefficient $a=6$, Figure 6 describes the change of retailer's optimal order quantity with the credit guarantee coefficient $\lambda$ in decentralized and centralized system. Figure 7 describes the change of SCF participants and system's optimal profit with the credit guarantee coefficient $\lambda$ in decentralized and centralized system.

1) In centralized system, the retailer's optimal order quantity and the optimal profit of the supply chain finance system do not change with the credit guarantee coefficient $\lambda$.

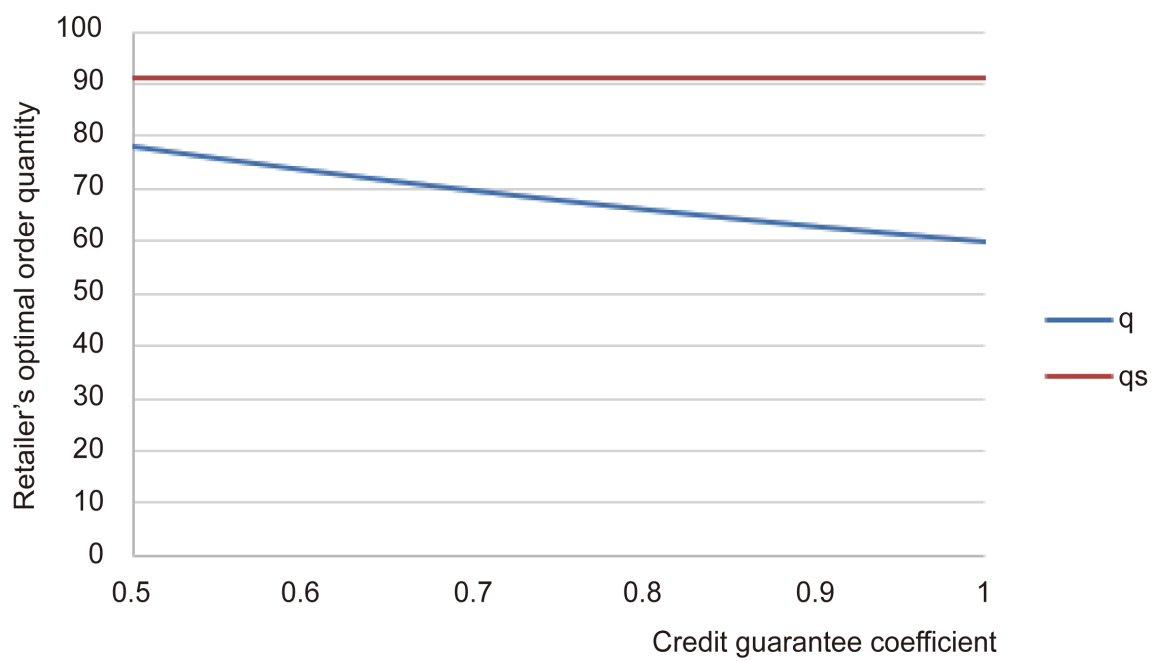

Figure 6. Retailer's optimal order quantity under different credit guarantee coefficient. 


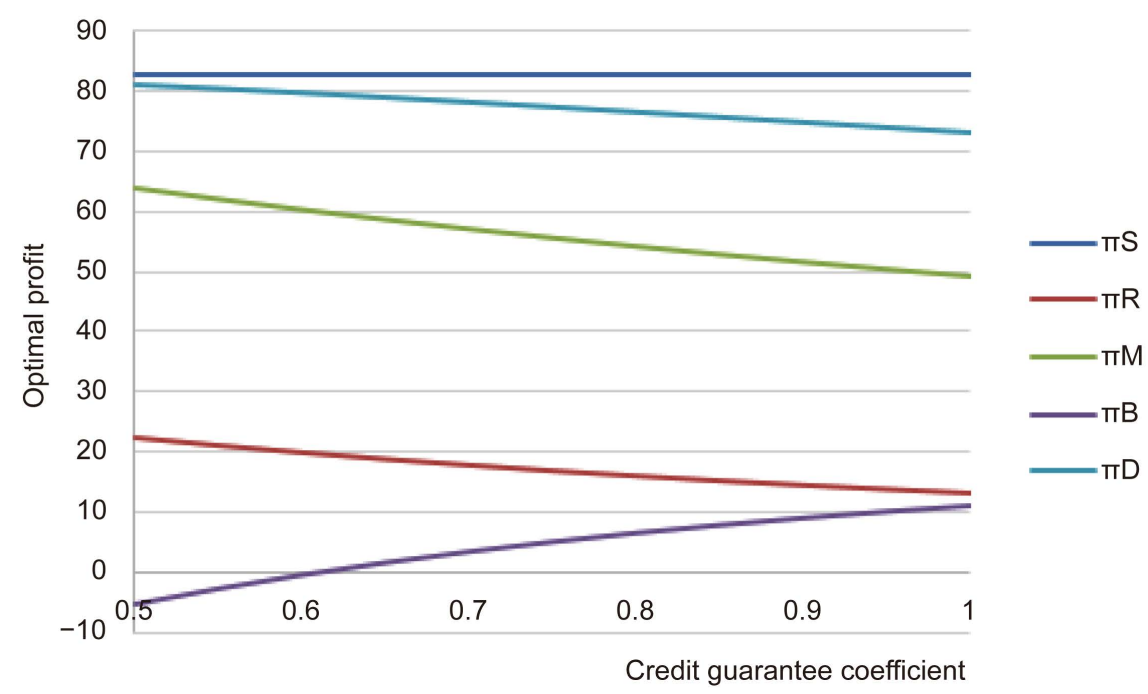

Figure 7. SCF participants and system's optimal profit under different credit guarantee coefficient.

2) In decentralized system, the optimal order quantity of the retailer decreases with the increase of $\lambda$. The bank's optimal profit increases with the increase of $\lambda$ at a faster rate. The optimal profit of retailer and manufacturer decreases with the increase of $\lambda$, whose variation tendency is approximately the same. The sum of the three SCF participants' optimal profit in the decentralized system also decreases with the increase of $\lambda$.

3) When $\lambda$ is below about 0.6 , the bank's best profit is negative. The bank's optimal profit is positive only when $\lambda$ is large enough.

4) According to Figure 7, the optimal profit of the supply chain financial system in centralized system is always higher than the sum of the three SCF participants' optimal profit in the decentralized system. The higher $\lambda$ is, the larger optimal profit gap between the decentralized and centralized system is.

\section{Conclusions}

This paper studies the decision-making problem of three echelon supply chain, retailer-manufacturer-bank, in centralized and decentralized systems. Through the calculation, it is proved that under the credit guarantee of the core enterprise, the retailer has the optimal ordering strategy, and the core enterprise has the optimal wholesale price. Besides, the optimal profit of the SCF system in centralized system is always higher than the sum of the three SCF participants' optimal profit in the decentralized system.

The retailer's loan coefficient and the credit guarantee coefficient can narrow the optimal profit gap between the decentralized and centralized system to a certain extent. It is embodied in two aspects. On the one hand, when the retailer's loan coefficient is consistent with the wholesale price, that the retailer's loan amount is 0 , the optimal profit of the SCF system in centralized system is the same as the sum of the three SCF participants' optimal profit in the decentralized system. Considering that the principal and interest of the retailer are the 
retailer's total sales when the supply chain financial system is balanced, i.e. the retailer's profit is zero. Hence, the retailer's loan coefficient can narrow the optimal profit gap between the decentralized and centralized system to a certain extent. On the other hand, the smaller $\lambda$ is, the narrower optimal profit gap between the decentralized and centralized system is.

Considering that the bank's expect profit is negative when the credit guarantee coefficient is too small, the credit guarantee coefficient can narrow the optimal profit gap between the decentralized and centralized system to a certain extent.

There are also shortcomings in this paper. In this paper, the decisions of parameter $a$ and $\lambda$ are not taken into account in the game model, but the influences on the game result are analyzed. On the other hand, this paper considers a simpler supply chain model. The actual situation is that supply chain finance financing is facing a more complex supply chain system, and involves dynamic evolution.

\section{Acknowledgements}

This research was supported by "the Fundamental Research Funds for the Central Universities” (2015ZKYJZX02).

\section{References}

[1] Dada, M. and Hu, Q. (2008) Financing Newsvendor Inventory. Operations Research Letters, 36, 569-573. https://doi.org/10.1016/j.orl.2008.06.004

[2] Srinivasa Raghavan, N.R. and Mishra, V.K. (2011) Short-Term Financing in a CashConstrained Supply Chain. International Journal of Production Economics, 134, 407-412. https://doi.org/10.1016/j.ijpe.2009.11.014

[3] Kouvelis, P. and Zhao, W. (2012) Financing the Newsvendor: Suppliervs. Bank, and the Structure of Optimal Trade Credit Contracts. Operations Research, 60, 566-580. https://doi.org/10.1287/opre.1120.1040

[4] Yan, N., Dai, H. and Sun, B. (2014) Optimal Bi-Level Stackelberg Strategies for Supply Chain Financing with Both Capital-Constrained Buyers and Sellers. Applied Stochastic Models in Business and Industry, 30, 783-796.

https://doi.org/10.1002/asmb.2021

[5] Yan, N.N., Sun, B.W., Zhang, H. and Liu, C.Q. (2016) A Partial Credit Guarantee Contract in a Capital-Constrained Supply Chain: Financing Equilibrium and Coordinating Strategy. International Journal of Production Economics, 173, 122-133. https://doi.org/10.1016/j.ijpe.2015.12.005

[6] Yan, N.N. and Sun, B.W. (2011) Optimal Strategies for Supply Chain Financing System Based on Warehouse Receipts Financing with Credit Line. System Engineering-Theory \& Practice, No. 9, 1674-1679.

[7] Lu, Q.H. and Zeng, L.F. (2012) Research on Decision-Making and Value of Supply Chain Financing with Accounts Receivables. Journal of Management Sciences in China, 5, 10-18.

[8] Yi, Z. (2012) Study on Loan-to-Value Ratios of Bank in the Supply Chain Finance. Chinese Journal of Management Sciences, No. 1, 102-108.

[9] Li, C. and Luo, J.W. (2016) Revenue-Sharing Coordination Mechanism for a Finan- 
cial Constrained Supply Chain Based on Advance Payment. Chinese Journal of Management, No. 5, 763-771.

[10] Chen, L., Peng, J., Liu, Z. and Zhao, R. (2016) Pricing and Effort Decisions for a Supply Chain with Uncertain Information. International Journal of Production Research, 55, 264-284. https://doi.org/10.1080/00207543.2016.1204475

[11] Liu, Z., Zhao, R., Liu, X. and Chen, L. (2016) Contract Designing for a Supply Chain with Uncertain Information Based on Confidence Level. Applied Soft Computing, 56, 617-631. https://doi.org/10.1016/j.asoc.2016.05.054

[12] Chen, H., Wang, X., Liu, Z. and Zhao, R. (2017) Impact of Risk Levels on Optimal Selling to Heterogeneous Retailers under Dual Uncertainties. Journal of Ambient Intelligence and Humanized Computing, 1-19.

https://doi.org/10.1007/s12652-017-0481-9

Submit or recommend next manuscript to SCIRP and we will provide best service for you:

Accepting pre-submission inquiries through Email, Facebook, LinkedIn, Twitter, etc. A wide selection of journals (inclusive of 9 subjects, more than 200 journals)

Providing 24-hour high-quality service

User-friendly online submission system

Fair and swift peer-review system

Efficient typesetting and proofreading procedure

Display of the result of downloads and visits, as well as the number of cited articles

Maximum dissemination of your research work

Submit your manuscript at: http://papersubmission.scirp.org/

Or contact jamp@scirp.org 